Proc. Indian Acad. Sci. (Earth Planet. Sci.), Vol. 98, No. 1, April 1989, pp. 91-109.

(C) Printed in India.

\title{
New seismological results on the tectonics of the Garhwal Himalaya
}

\author{
K N KHATTRI, RAMESH CHANDER, V K GAUR*, I SARKAR and \\ SUSHILKUMAR \\ Department of Earth Sciences, University of Roorkee, Roorkee 247667 , India \\ * National Geophysical Research Institute, Uppal Road, Hyderabad 500007, India
}

\begin{abstract}
This paper reports data pertaining to 90 local earthquakes recorded during 1984-86 using seismographs in arrays of 5-7 stations deployed near the Main Central Thrust between Bhagirathi and Alakhananda valleys. The results which are also compared with 162 earthquakes recorded in 1979-80 provide a local view that refines and complements information recorded at distant seismic stations.
\end{abstract}

Keywords. Garhwal Himalaya; local earthquakes; seismo-tectonic model; focal mechanisms.

\section{Introduction}

Broadly speaking, the Garhwal Himalaya, drained by the Yamuna, the Bhagirathi and the Alakhnanda rivers constitute the middle part of Burrard's and Gansser's Kumaun Himalaya extending from the Sutlej to the Kali river. The meizoseismal area of the 1905 Kangra earthquake (magnitude 8.6) extended into the western part of the Garhwal Himalaya (Molnar, this volume). The eartern part of the region marks the western end of the 700-km-long seismic gap extending up to the rupture zone of the 1934 Bihar-Nepal earthquake (magnitude 8.4). The region has not experienced a major earthquake (magnitude $>\mathbf{8 . 0}$ ) in recorded history and unless it happens to be an exceptional segment of the Himalaya collision zone distinguished only by strain releases through small and intermediate magnitude earthquakes, the ambient stresses here must be fairly high.

In this study, data for 90 local earthquakes recorded during 1984-86, using portable seismographs in arrays of 5 to 7 stations deployed in the vicinity of the Main Central Thrust (MCT) between Bhagirathi and Alakhnanda valleys, are reported and considered along with the previously published results for 162 earthquakes recorded in 1979-80 in the vicinity of the MCT between the Yamuna and Bhagirathi valleys. The epicentres of these 252 earthquakes define a $140-\mathrm{km}$-long seismic belt stretching from northwest of the Yamuna valley southeastward upto the Alakhnanda valley. The width of the belt varies between 30 and $50 \mathrm{~km}$. The estimated focal depths of 225 earthquakes were less than $13 \mathrm{~km}$, while those of the remaining 27 were between 13 and $23 \mathrm{~km}$. The first motion data for 50 earthquakes provided two composite focal mechanism solutions. Data for 29 earthquakes defined a strike-slip solution. Twenty of these earthquakes occurred NW of the Bhagirathi river. Data for the other 21 earthquakes defined a thrust solution. Nineteen of these earthquakes occurred SE of the Bhagirathi river. The maximum compressive stress direction is very nearly identical in both cases, being oriented NE-SW. The thrust solution yields a modest plunge of $15^{\circ}$ to the NE for the axes of maximum compressive stress. 
The local earthquakes considered here are viewed primarily as arising from fresh brittle failures or renewed slips on pre-existing planes of weakness in the overriding plate involved in the Himalayan convergence. A general stress-state conducive to thrust or reverse faulting appears to exist in the overriding plate from the ground surface down to its lower boundary where it is in contact with the under-thrusting Indian plate. The strike-slip earthquakes may be explained by postulating a modification of this stress-state through tensile stresses due to a flexure of the overriding plate over a ridge-like feature on the top surface of the subducting plate. The ridge would be a northeastward salient of the Pre-Cambrian Aravalli ranges of Rajasthan whose outcrops can be seen as far north as New Delhi and which probably continue northeastward under the Sindhu-Ganga alluvium and even the Lesser and High Himalaya. The crest of the ridge may be approximately along $78^{\circ} \mathrm{E}$. The tensile stresses generated on this account would attenuate with distance perpendicular to the ridge crest. The ridge which is transverse to the Himalaya perhaps decouples the rupture zone of the 1905 Kangra earthquake from the seismic gap that lies east of it, thereby facilitating the strain release on these segments at their separate rates.

The seismic belt associated with the Himalayan collision boundary has so far been delineated mainly on the basis of teleseismic and regional data. Here we present information about earthquake locations and source mechanisms for a part of the Garhwal Himalaya (figure 1) segment of the seismic belt as gleaned from seismograms recorded locally, using portable seismographs deployed in arrays of small areal extent. Combined with data and results from Gaur et al (1985) (hereafter referred to as paper I) this provides a unique local view that refines and complements the information recorded at distant seismic stations.

\subsection{Nomenclature}

The administrative districts of Pauri, Chamoli, Uttarkashi, Tehri and Dehradun constitute the region of the Garhwal Himalaya. This region forms a somewhat bigger middle third of Burrard's (see Wadia 151, p. 9 and Gansser 1964, p. 8) "Kumaon Himalaya" which extended from Sutlej to Kali river. Alternatively, the region forms the western, bigger part of Valdiya's $(1980$, p. 1) "Kumaun Himalaya" which run from the state boundary between Himachal Pradesh and Uttar Pradesh to the international boundary between India and Nepal along the Kali river. The Yamuna, the Bhagirathi and the Alakhnanda are the main rivers of the Garhwal Himalaya.

We shall have occasion to use the terms Lesser and High Himalaya. Originally (Wadia 1951, p. 10) these terms denoted physiographic provinces running along the entire length of the Himalaya. "The High (or Great) Himalaya constitute the innermost line of high ranges rising above the limit of perpetual snow. Their average height extends to $6-7 \mathrm{~km}$. The Lesser Himalaya are a series of ranges closely related to the former but of lower elevation, seldom rising much above 4 to $5 \mathrm{~km}$ " (Wadia 1951). Gansser (1964) used terms Lower and Higher Himalaya with the connotation that the boundary between the Lesser and Higher Himalaya is marked by the Main Central Thrust (MCT), the other boundary of the Lesser Himalaya being the Main Boundary Thrust (MBT). According to Valdiya $(1980$, p. 10$)$, the highest point in Garhwal Himalaya is Nag Tibba (elev. $3022 \mathrm{~m}$ ), the general elevations being in the range of 1500 to $2500 \mathrm{~m}$.

We shall call the seismic belt in the Garhwal Himalaya as GLHSB, short for 


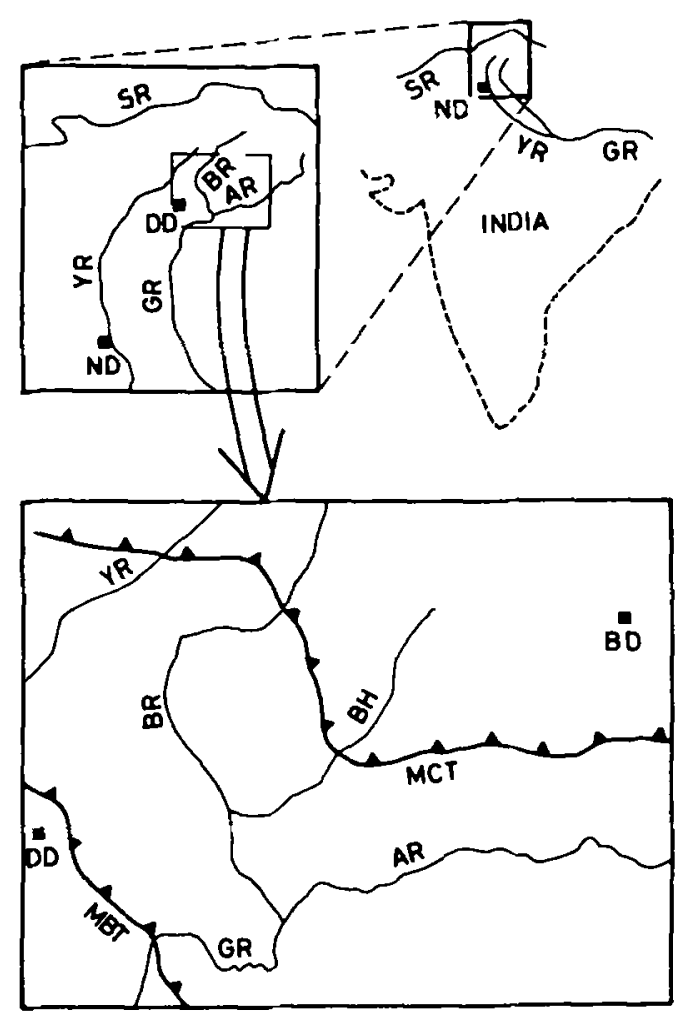

Figure 1. Showing the location of the area of interest in the Himalaya. Abbreviations for river names are: $A R$, Alakhnanda river, $B H, B$ hilangana river, $B R$, Bhagirathi river, GR, Ganga river; SR, Sutlej river and YR, Yamuna river. Abbreviations for place names are: BD, Badrinath; DD, Dehradun and ND, New Delhi. The thrusts shown are the Main Boundary Thrust (MBT) and the Main Central Thrust (MCT).

Garhwal Lesser Himalaya Seismic Belt. This appellation appears to be strictly true with respect to the earlier definition of the Lesser Himalaya. It takes only minor liberties with Gansser's Lower Himalaya concept because at places in Garhwal the seismic belt appears to lie some distance NE of the MCT.

\subsection{Relevance of the study}

Four large earthquakes (magnitudes $8 \cdot 7,8 \cdot 6,8 \cdot 4$ and $8 \cdot 7$, Richter 1958) have occurred in different parts of the Himalaya in the last nine decades. But the last of them occurred 37 years ago. The meizoseismal area of the 1905 Kangra earthquake (magnitude 8.6) extended well into Garhwal Himalaya from the west. The portion of Garhwal Himalaya immediately east of this is a part of the nearly $700 \mathrm{~km}$-long seismic gap recognized by Seeber and Armbruster (1981), Khattri and Tyagi (1983) and Khattri (1987). The region is not known to have experienced a magnitude 8 or greater earthquake in recorded history and unless it happens to be an exceptional segment of the Himalaya collision zone in which most of the stress is released through intermediate magnitude earthquakes, the ambient stresses here must be fairly high. 
This is a strong motivation for investigating the ongoing seismicity and earthquake source processes in the Garhwal Himalaya.

Further, as noted above, the Garhwal Himalaya are drained by three mighty perennial rivers with numerous tributaries. The region thus possesses a vast potential for irrigation and generation of hydroelectric power. A large number of multipurpose river valley schemes have been conceived for the region and many of them are under execution or in advanced stages of design. The $260 \mathrm{~m}$ high earth and rockfill Tehri Dam on the Bhagirathi river is in the early stages of execution. Detailed seismicity information would be vital for planning seismic risk mitigation measures for these projects. Scientifically too, detailed information about earthquake processes in the region would be useful for evolving earthquake prediction and seismotectonic models.

\subsection{Local recording}

Sporadic recording of local earthquakes using one to three seismograph stations has been carried out in the Bhagirathi valley between 1974 and 1977 (Agarwal and Kumar 1982). Four permanent photographically recording seismographs have also been present for some time and are still in operation in the region (Srivastava 1986). But the instruments have low magnification and the array configuration is unsuitable for detecting and locating many local earthquakes. Results of recording local earthquakes with a five-station array (largest dimension $45 \mathrm{~km}$ ) during 1979-80 were reported in paper I. The array stations were located in the Yamuna and the Bhagirathi valleys in the vicinity of the MCT. We report here analyses of local earthquake data recorded with 5 to 7 element seismograph arrays during 1984-86 in the region immediately SE of that considered in paper I. This region lies between Bhagirathi and Alakhnanda valleys in the vicinity of $\mathrm{MCT}$.

\subsection{Review}

A cardinal fact about the Himalayan seismic belt is that its overall definition so far rests on regional and teleseismic observations of intermediate magnitude earthquakes. The information has been supplemented in recent years by data from a few local networks (Seeber et al 1981; Gaur et al 1985; Srivastava 1986; Khattri 1987). Hence most of the articles about seismicity of Himalaya refer to the four large and numerous intermediate magnitude earthquakes. We recall here the available models of Himalaya against which we compare our results and conclusions.

The Himalaya is considered to be the result of continent-continent collision of the Indian and Eurasian plates (e.g. LeFort 1975; Valdiya 1980; Seeber et al 1981; Khattri 1987). The two continents have sutured along the Indus Suture Thrust. Portions of the northern edge of the Indian plate have been thrusted southwards as a result of continued convergence between India and Eurasia. Two major intraplate thrusts are the MCT and MBT. According to one model, the so-called evolutionary model (e.g. LeFort 1975), the MCT and MBT are similar in nature and along these crustal slices of the Indian plate have been thrusted southwards. In the alternative steady-state model (e.g. Seeber et al 1981; Seeber and Armbruster 1981; Ni and Barazangi 1984) the MBT and MCT are different in character. The MCT is a thrust fault that involves the upper crust. The region south of the MCT constitutes a sedimentary wedge consisting of the Ganga foredeep, the other (Siwalik) Himalaya, and the Lesser Himalaya. This 
wedge is thought to be underlain by a quasi-horizontal detachment surface coinciding with the upper surface of the subducting Indian lithosphere. Earthquakes of intermediate magnitudes occur near the northern margin of the detachment whereas the great earthquakes further to the south are caused by slip on this detachment.

The faultplane solutions and focal depths determined by Baranowski et al (1984) confirm the above model, though they, as well as Lyon-Caen and Molnar (1983), favour a model in which the upper portion of the Indian slab under the Greater Himalaya has been sliced and thrusted southward.

On a more local scale, for the Garhwal Himalaya specially, Agarwal and Kumar (1982) reported their tripartite observations of seismicity in the Bhagirathi valley. They noted sporadic activity along the MCT.

A belt of local earthquake epicentres was defined over a distance of about $70 \mathrm{~km}$ from the analyses reported in paper $I$. The best data pertained to the region between the Yamuna and the Bhagirathi valley which was enclosed within the recording array. In this region the seismic belt was observed to lie distinctly south of the MCT which was thus considered to be seismically inactive in the region. A sinistral offset along on E-W line was observed in the trend of the belt. A composite focal mechanism solution indicated strike-slip faulting. The strikes of the two nodal planes were $\mathrm{N}-\mathrm{S}$ and $\mathrm{E}-\mathrm{W}$. The latter plane was inferred to be the fault plane because the sinistral relative motion observed across it coincided with the sinistral E-W offset in the seismic belt. The focal depth of the majority of the earthquakes was less than $10 \mathrm{~km}$ and a case was made that the seismicity may be confined only to the top $20 \mathrm{~km}$ of the crust.

The new results presented in this study enable the belt of local earthquakes to be defined over a further distance of $70 \mathrm{~km}$ between the Bhagirathi and Alakhnanda valleys. The estimated focal depths of earthquakes are again predominantly shallow. A composite 'thrust' solution has been observed for earthquakes SE of the Bhagirathi valley. The seismicity in the Garhwal Himalaya appears to be confined primarily to the overriding slice of the plate which may be composed of the sedimentary wedge and the Tethyan slab according to Seeber and Armbruster (1981), of the upper portion of the Indian plate itself (Baranowski et al 1984).

\section{Seismicity}

The sites in the Bhagirathi and Alakhnanda valley occupied with portable seismographs during parts of 1984-86 are shown in figure 2 . The details of the station networks operated are given in table 1. Earthquakes occurring locally as well as at regional and teleseismic distances were recorded. But we present data for local

Table 1. Details about seismograph arrays operated during 1984-86.

\begin{tabular}{lc}
\hline List of stations in the array & Period of operation \\
\hline AKM, CHA, LMG & November-December 1984 \\
AKM, CHA, GHU, LMG, DHO & January-March 1985 \\
AKM, CHA, GHU, DHO, LAT & April-June 1985 \\
AKM, CHA, GHU, DDA, DAB, TIL, UKH & October 1985-June 1986 \\
\hline
\end{tabular}

Note: The station codes match with those shown in figure 2 
Table 2. Seismic wave speed model adopted for the Garhwal Lesser Himalaya

\begin{tabular}{lccc}
\hline & $\begin{array}{c}\text { Thickness } \\
(\mathbf{k m})\end{array}$ & $\begin{array}{c}P \text { wave speed } \\
(\mathbf{k m} / \mathbf{s})\end{array}$ & $\begin{array}{c}S \text { wave speed } \\
(\mathbf{k m} / \mathbf{s})\end{array}$ \\
\hline Layer 1 & 17 & $5 \cdot 2$ & 2.97 \\
Layer 2 & Infinite & 6.0 & 3.43 \\
\hline
\end{tabular}

earthquakes only because by doing so at least the estimates of epicentral locations can be relied upon for earthquakes occurring within or close to a seismograph station array.

\subsection{Data analysed}

The data for only those earthquakes were analysed which provided a minimum of five-wave arrival times in the following combinations.

(i) $P$ readings at 5 stations;

(ii) $P$ readings at 4 stations and $S$ reading at one of the 4 stations;

(iii) $P$ readings at 3 stations and $S$ readings at two of these stations.

A restriction was also imposed that the difference in arrival times of $P$ and $S$ waves should be less than $10 \mathrm{~s}$. The aim was to improve the chances that the first arriving $P$ wave would be a direct wave. A simple application of the head wave theory (Dobrin 1976) shows that in the context of the wave speed model of table 2 , this would be the case for earthquakes with focal depths less than $13 \mathrm{~km}$. Still, in every case, an attempt was made to use as much data for an earthquake as possible and available within these restrictions.

\subsection{Hypocentral parameter estimation procedure}

The same computer program was employed for this purpose as discussed and used in paper I.

\subsection{Crustal model}

Estimation of the four hypocentral parameters (viz. epicentral latitude and longitude, hypocentral depth and origin time) from arrival times of $P$ and $S$ waves requires information about the distribution of $P$ and $S$ wave speeds between the earthquake focus and the stations. We are unaware that any study elucidating this information has been carried out in the region of interest, namely the region along the GLHSB between the Bhagirathi and the Alakhnanda rivers. We adopted for the purpose a uniform half-space model with a $P$ wave speed of $5 \cdot 2 \mathrm{~km} / \mathrm{s}$ and $P$ to $S$ wave speed ratio of 1.75 , close to 1.73 for a Poisson solid. This $P$ wave speed is the same as estimated by Chander et al (1986) for the region in the vicinity of the MCT between Yamuna and Bhagirathi valleys immediately to the NW of the region of interest here. We offer the following remarks in defence of this simple wave speed model. Many investigators (e.g. Kaila et al 1968; Tandon and Dubey 1973; Verma 1974) have attempted to estimate 
the seismic wave speed model for the Himalayan region. But none of these results apply even to the Garhwal Himalaya. However the data collected by us during 1979-80 have also been used to estimate seismic wave speeds in the first and second crustal layers. The above mentioned result $(5.2 \mathrm{~km} / \mathrm{s})$ for the first crustal layer applies to the region between Yamuna and Bhagirathi valleys near the MCT, while the result $(6.0 \mathrm{~km} / \mathrm{s})$ for the second crustal layer (Kumar et al 1987) applies strictly to the region immediately NW of that. Both these values have been adopted for the region of the GLHSB southeast of the Bhagirathi valley as being the values estimated for the region closest to the region of interest. The depth to the interface between the two layers has not been estimated in these studies. We assume that the interface in question is the thrust surface between the colliding lithospheric plates in the Lesser and High Himalaya. The surface may be delineated approximately by the foci of intermediate magnitude thrust earthquakes ( $\mathrm{Ni}$ and Barazangi 1984) in the Himalaya seismic belt. The depth to the interface beneath the MCT is estimated by us to be $17 \mathrm{~km}$ from Ni and Barazangi's figure 11 (middle part). The interface dip of $15^{\circ}$ has been estimated by $\mathrm{Ni}$ and Barazangi but may be ignored when only the order of magnitude of the travel times of head waves travelling predominantly parallel to the strike of the interface is being considered. Since only eight out of 92 earthquakes had estimated focal depths below $13 \mathrm{~km}$ in the context of the model of table 2 , these were the only earthquakes for which there was a need to consider at least a two-layered half space model. This justifies the use of the simple half-space model on grounds of convenience and its relatively minor influence on the results obtained.

\subsection{Seismicity results}

The stringent conditions on phase data discussed in the foregoing were met for only $\mathbf{4 1}$ earthquakes recorded during the 1984-85 season and 49 events during the 1985-86 season. The data for these 90 events are considered along with 162 events considered in paper I which met the same requirements. However, we recall that the hypocentral parameters of the latter events had been estimated using a $P$ wave speed of $5 \mathrm{~km} / \mathrm{s}$.

The 252 epicentres are plotted in figure 2 . The seismic belt delineated by these local events is compared with that defined by regionally and teleseismically located events for 1684 to 1985 in figure 3. Two depth sections along the perpendicular to the trend of the seismic belt (local earthquakes only) are shown in figures 4 and 5 . The coda magnitude of these events is in the range of 2 to 4.

\subsection{Belt of seismicity}

The 252 epicentres of the local earthquakes recorded during 1979-80 and 1984-86 define a definite seismic belt extending over a distance of about $140 \mathrm{~km}$ from NW of Yamuna river to Alakhnanda river. The width of the belt appears to vary between 30 and $50 \mathrm{~km}$. Around $78 \cdot 5^{\circ} \mathrm{E}$ longitude the belt appears to have a $50 \mathrm{~km}$ long, N-S trending offshoot to the south. The concentration of epicentres between Yamuna and Bhagirathi valleys clearly defines a sinistral E-W oriented offset in the belt (figure 2).

\subsection{Focal depth}

A frequency $/ \mathrm{km}$ table (table 3 ) and a histogram (figure 6) were prepared for the 


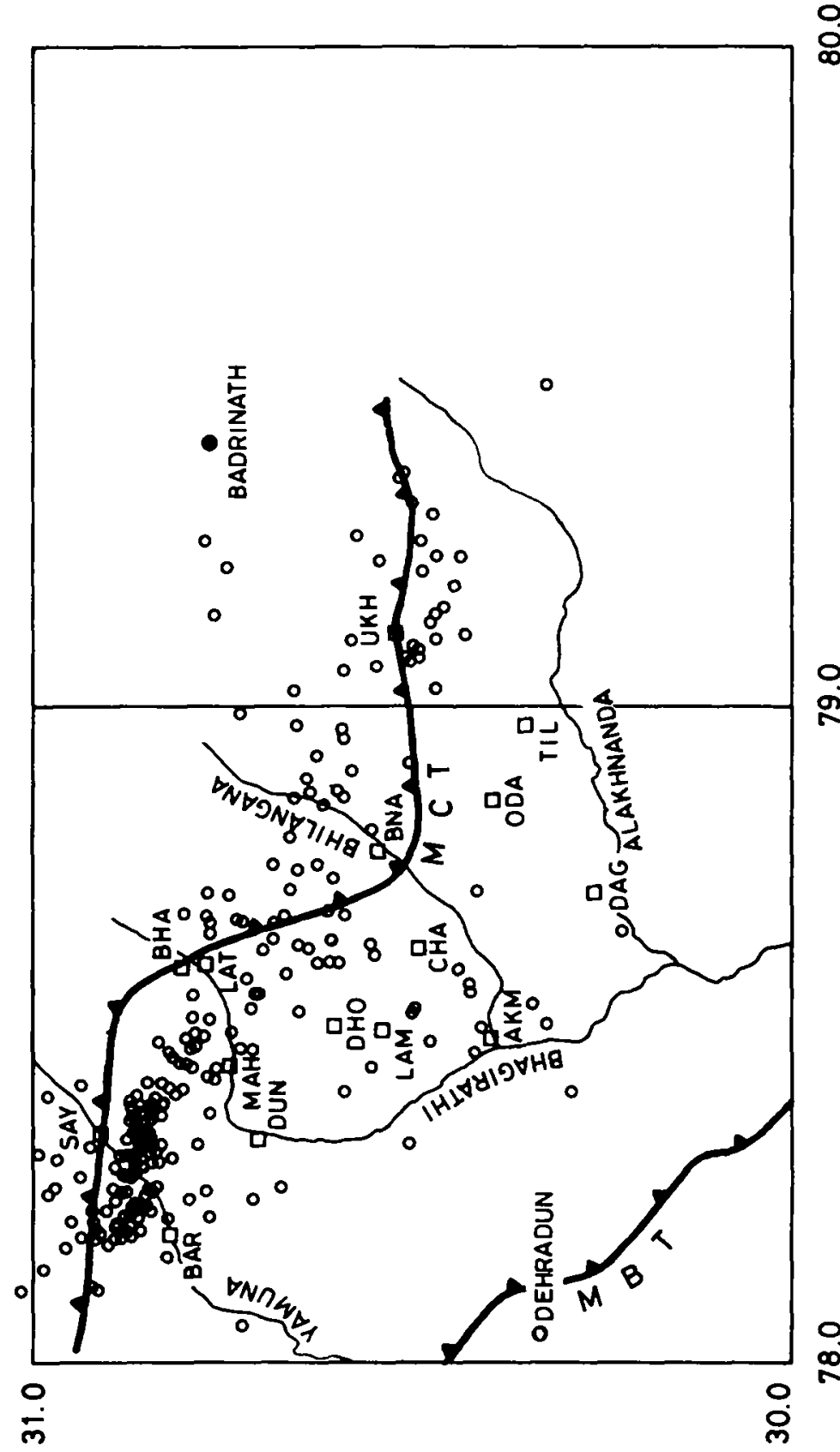

急

s.

品

염

㺃总

동

究 出

㐘

雪

동

ㅇ. 5

o

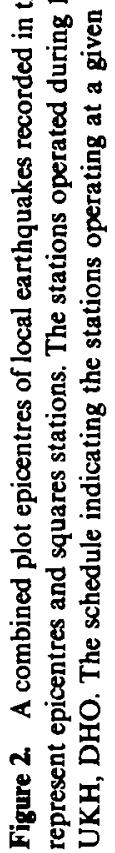




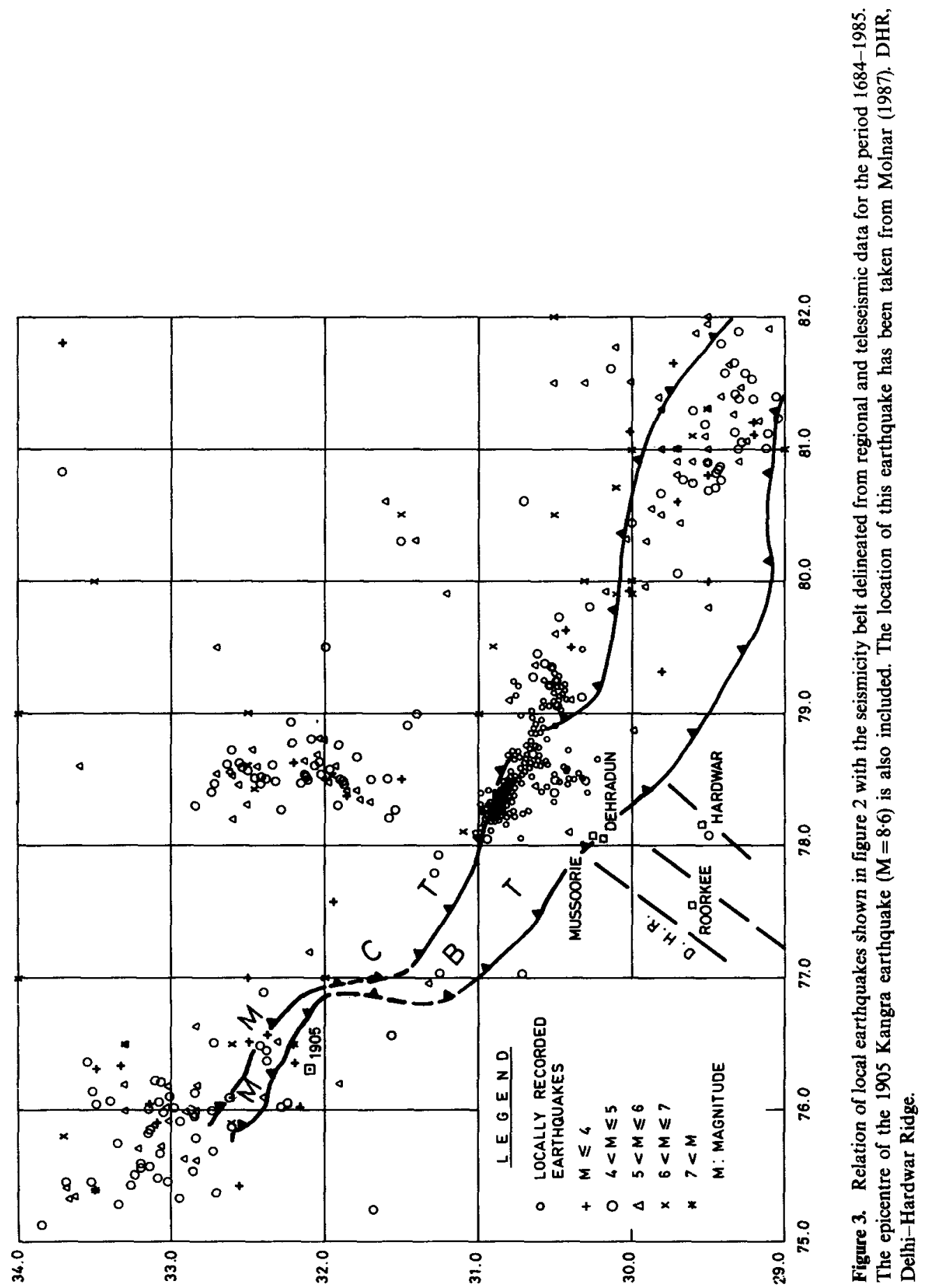



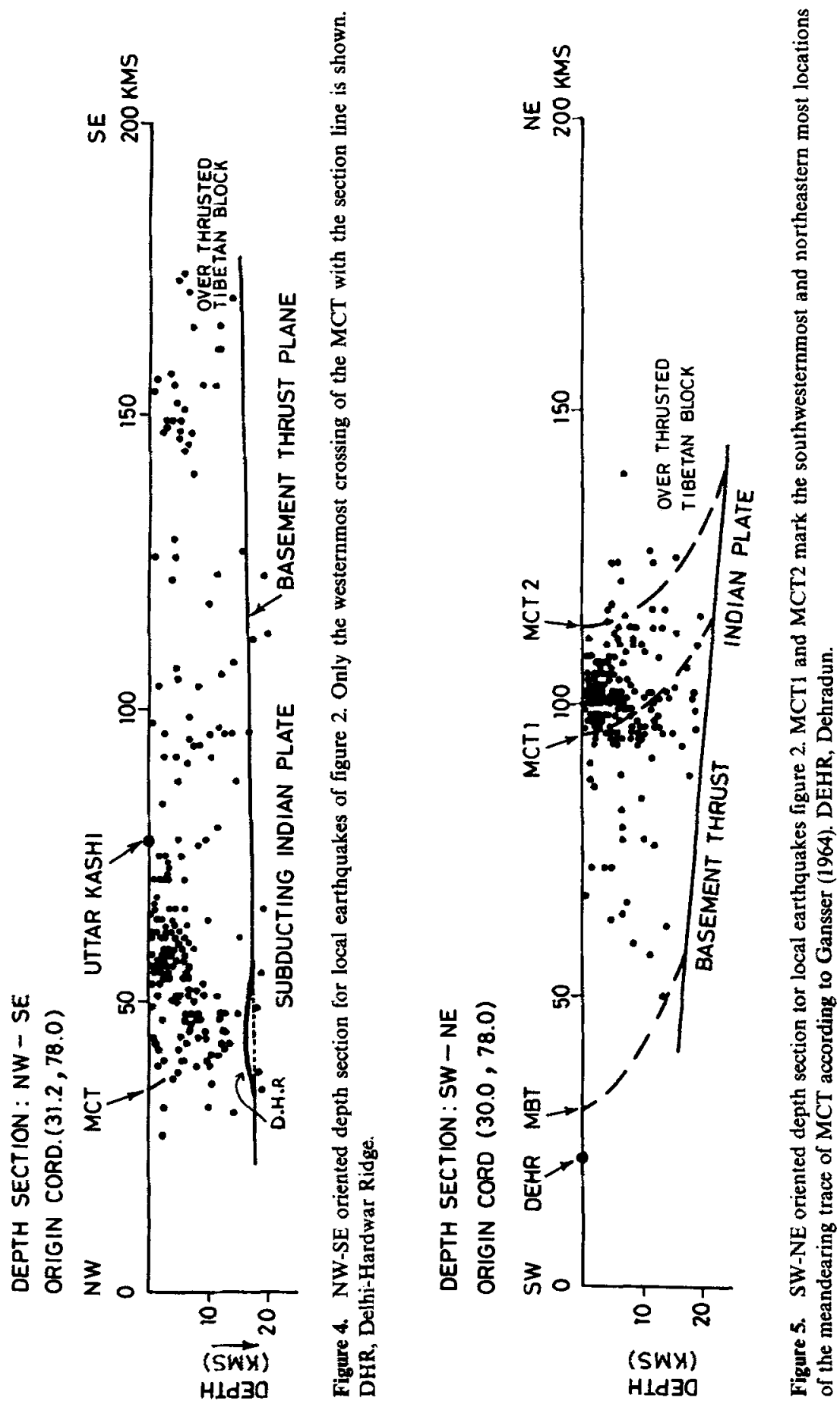
Table 3. Distribution of estimated focal depths in $1 \mathbf{~ k m}$ intervals.

\begin{tabular}{|c|c|c|}
\hline $\begin{array}{l}\text { Depth interval } \\
\text { (km) }\end{array}$ & $\begin{array}{c}\text { Number of } \\
\text { earthquakes } \\
\text { in the interval }\end{array}$ & $\begin{array}{c}\text { Cumulative } \\
\text { Number }\end{array}$ \\
\hline$-1-0$ & 1 & 1 \\
\hline $0-1$ & 20 & 21 \\
\hline $1-2$ & 23 & 44 \\
\hline $2-3$ & 25 & 69 \\
\hline $3-4$ & 19 & 88 \\
\hline $4-5$ & 20 & 108 \\
\hline $5-6$ & 22 & 130 \\
\hline $6-7$ & 25 & 155 \\
\hline $7-8$ & 11 & 166 \\
\hline $8-9$ & 16 & 182 \\
\hline $9-10$ & 11 & 193 \\
\hline $10-11$ & 11 & 204 \\
\hline $11-12$ & 12 & 216 \\
\hline $12-13$ & 9 & 225 \\
\hline $13-14$ & 9 & 234 \\
\hline $14-15$ & 3 & 237 \\
\hline $15-16$ & 4 & 241 \\
\hline $16-17$ & 2 & 243 \\
\hline $17-18$ & 3 & 246 \\
\hline $18-19$ & 2 & 248 \\
\hline $19-20$ & 0 & 248 \\
\hline $20-21$ & 2 & 250 \\
\hline $21-22$ & 1 & 251 \\
\hline $22-23$ & 1 & 252 \\
\hline
\end{tabular}

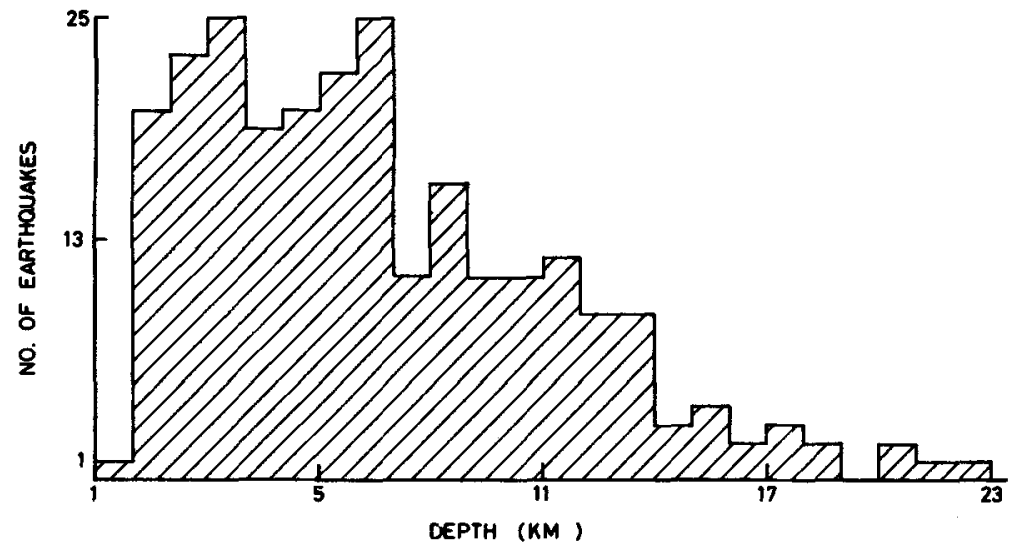

Figure 6. Histogram showing the number of earthquakes versus depth of focus for an estimated 252 earthquakes. 
estimated focal depths of the 252 earthquakes. The estimated focal depth did not exceed $23 \mathrm{~km}$ in any case. It was less than $10 \mathrm{~km}$ for 193 earthquakes and between 10 and $13 \mathrm{~km}$ for another 32 earthquakes. In all 27 (or about $10 \%$ ) earthquakes were assigned estimated focal depths in the range of 13 to $23 \mathrm{~km}$. The preponderance of very shallow earthquakes among the local earthquakes considered is manifest.

\subsection{Activity with time}

The frequency of earthquake occurrence in time is not uniform along the trend of the GLHSB. The region with the highest level of activity in this regard is the part of the belt between the Yamuna and Bhagirathi valleys. The next most active part of this stretch of the belt is considered on available data to be between the Mandakini and Alakhnanda rivers. This stretch of the belt appears to be most active, however, when the number of earthquakes located from regional and teleseismic observation in the period $1684-1985$ is considered.

\section{Focal mechanisms}

Focal machanisms of earthquakes have provided crucial evidence for sea floor spreading and plate tectonic hypotheses. Fitch (1970) presented the first focal mechanism solutions based on teleseismic and regional data for earthquakes in the Himalayan region. The results for the four earthquakes which occurred just east of Garhwal and were considered by Fitch showed support for the view that the Indian lithospheric plate was underthrusting the Himalaya. Subsequently many other investigators have presented such solutions for the Himalaya, but none of them referred particularly to the Garhwal Himalaya. Among the Himalaya earthquakes with available focal mechanism solutions, six occurring in the India-Nepal Border region immediately east of the Garhwal Himalaya showed thrust-faulting and had reliably determined focal depths in the range of 12 to $18 \mathrm{~km}$ (Ni and Barazangi 1984; Baranowski et al 1984).

The seismograms recorded during 1984-86 were also examined for the sense of ground motion in the first $P$ waves. Reliable readings were obtained at one or more stations for 28 earthquakes. The data were consistent with two distinct composite focal mechanism solutions as follows.

Data from 20 earthquakes were consistent enough to yield the composite solution of figure 7. Five of the earthquakes occurred at focal depths of 15 to $20 \mathrm{~km}$. We take the NE dipping nodal plane with reverse fault motion as the fault plane. This is consistent with the view held by earlier workers (e.g. Fitch 1970; Chandra 1978) for Himalayan earthquake to take the northerly dipping plane as the fault plane. $\mathrm{Ni}$ and Barazangi (1984) and Baranowski et al (1984) reported thrust faulting in the 12 to $18 \mathrm{~km}$ range. The $\mathrm{NE}$ dipping plane of figure 6 has a dip of $60^{\circ}$ and it should strictly be termed a reverse fault. Since it refers mainly to shallower earthquakes, it is in conformity with the geological observations and opinion (e.g. Valdiya 1986) that the thrust faults in the Himalaya are listric with steeper dips at shallow depths and gentler dips at greater depths. Accordingly, we also call our reverse fault solution as a 'thrust' solution. Numerical data used for this solution is given in table 4.

Data from eight earthquakes were found to be consistent with the same strike-slip 


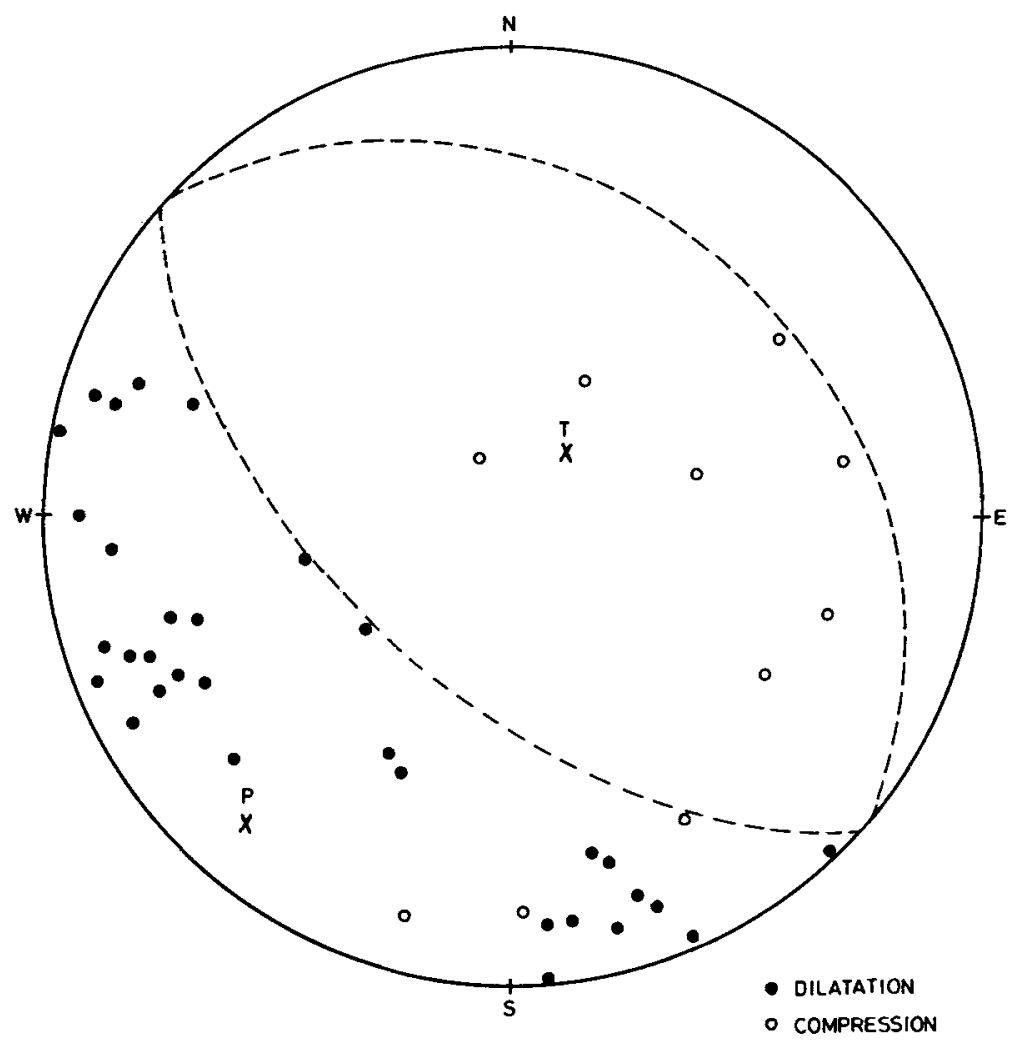

Figure 7. Composite focal mechanism solution in which only data from 1984-86 were involved. Equal area projection of the upper half of the focal sphere is shown. P and T mark the positions of the pressure and tension axes. The north-easterly dipping nodal plane is identified as the fault plane.

Table 4. Numerical data for the thrust solution of figure 6.

\begin{tabular}{|c|c|c|}
\hline & Strike & Dip \\
\hline Nodal plane 1 & $\mathrm{~N} 48^{\circ} \mathrm{W}-\mathrm{S} 48^{\circ} \mathrm{E}$ & $60^{\circ}$ along $N 42^{\circ} \mathrm{E}$ \\
\hline Nodal plane 2 & $\begin{array}{c}\mathrm{N} 48^{\circ} \mathrm{W}-\mathrm{S} 48^{\circ} \mathrm{E} \\
\text { Trend }\end{array}$ & $\begin{array}{c}30^{\circ} \text { along S42 } \\
\text { Plunge }\end{array}$ \\
\hline Pressure axis & $\mathrm{N} 42^{\circ} \mathrm{E}-\mathrm{S} 42^{\circ} \mathrm{W}$ & $15^{\circ}$ along $N 42^{\circ} \mathrm{E}$ \\
\hline Tension axis & $\mathrm{N} 42^{\circ} \mathrm{E}-\mathrm{S} 42^{\circ} \mathrm{W}$ & $75^{\circ}$ along $S 42^{\circ} \mathrm{W}$ \\
\hline$b$ axis & $\mathrm{N} 48^{\circ} \mathrm{W}-\mathrm{S} 48^{\circ} \mathrm{E}$ & Nil \\
\hline
\end{tabular}

solution as obtained in paper I from 1979-80 recordings. Seven of the eight earthquakes had their epicentres in the SE part of the region where earthquakes used in solution of paper I had occurred. One of these seven earthquakes had an estimated focal depth of $17.7 \mathrm{~km}$ while the rest had focal depths shallover than $15 \mathrm{~km}$. The eight earthquakes occurred well inside the region of earthquakes contributing to the above 'thrust' solution. The data on first motion for these earthquakes are shown in figure 8 plotted on the data and strike-slip solution of paper I. The new data 1984-86 provide 


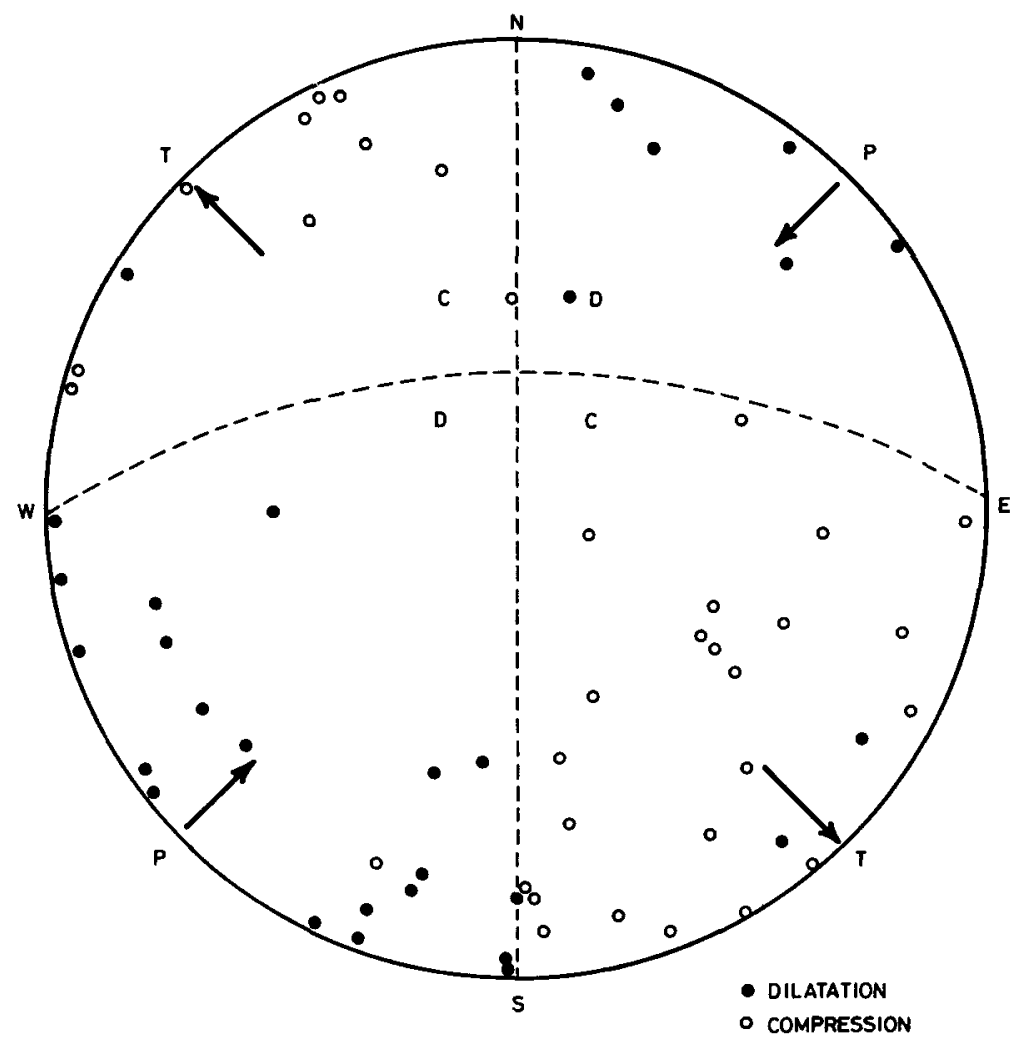

Figure 8. Composite focal mechanism solution in which 1984-86 data are combined with the 1979-80 data. Equal area projection of the upper half of the focal sphere is shown. $P$ and $T$ mark the positions of the pressure and tension axes.

no reason to change the earlier conclusion regarding $E-W$ nodal plane with sinistral relative motion as the fault plane, because it matches with a sinistral $\mathrm{E}-\mathrm{W}$ offset in the epicentral belt.

The epicentres of all earthquakes whose data were used in obtaining the composite solutions are shown in figure 9 where $T$ and $S$ mark the epicentral positions according to whether the corresponding first motion data appear in figures 6 or 7 respectively.

A remarkable feature of the composite solutions is that the direction of compressive stress is very nearly the same NE-SW in both cases (figures 6-8).

\section{Discussion}

It is evident from a review of literature and the foregoing analyses that investigations so far made, of Himalayan earthquakes based on magnitude, may be divided into three categories. Investigations of large (magnitude $>8$ ) earthquakes are mainly based on a visual inspection of the effects, in the four known cases of the last nine decades. Only for the 1934 Bihar-Nepal and 1950 Assam earthquakes are some instrumental investigations available (apart from estimation of hypocentral 


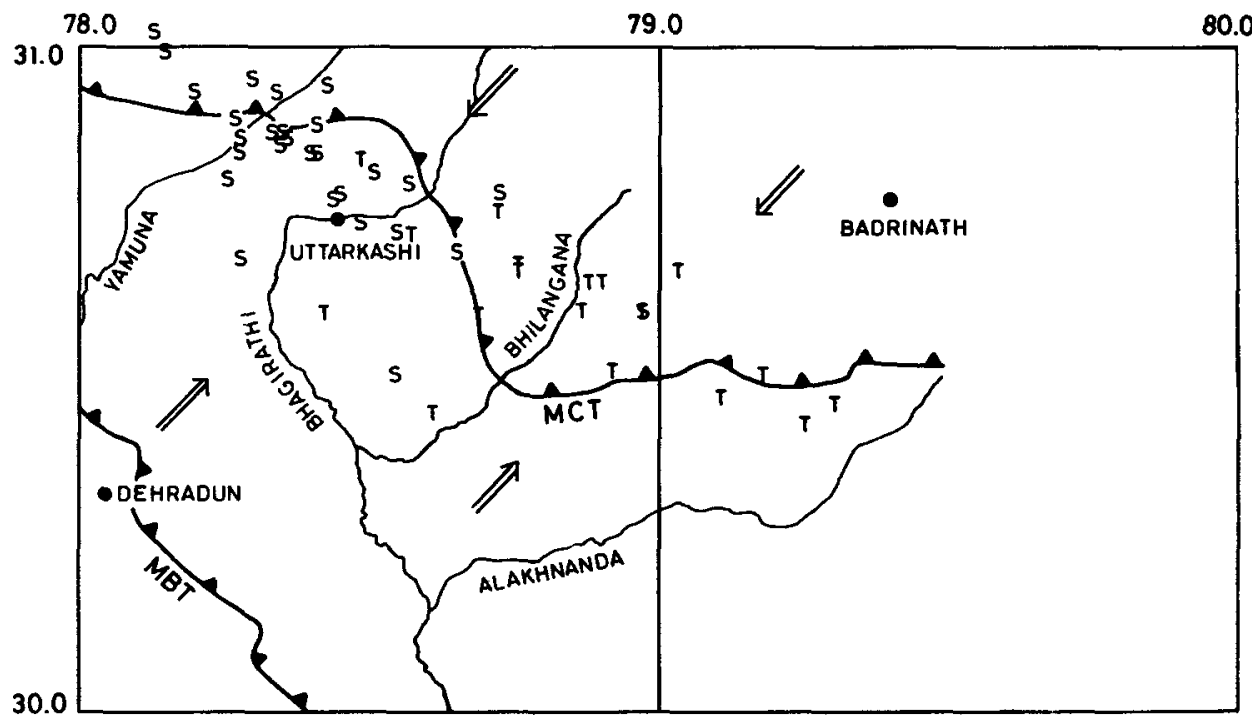

Figure 9. Epicentres of the earthquakes whose first motion data were used in the composite plots. $T$ and $S$ mark the epicentre positions according as the data for the corresponding earthquake were utilized in the thrust solution of figure 6 or strike-slip of figure 7. The large arrows indicate continuity in the maximum compressive stress direction across the $140 \mathrm{~km}$ length of the belt.

parameters and magnitudes). The intermediate magnitude earthquakes have been recorded at regional and teleseismic stations and have yielded data on hypocentral parameters, magnitudes, focal mechanisms, space-time seismicity studies, etc. In the last few decades local networks have started to yield information on small magnitude earthquakes in the Himalaya. The networks operated by our group in Garhwal Himalaya during 1979-80 and 1984-86 have yielded data on only one earthquake for which NOAA also has provided hypocentral data. In the modelling of seismicity of Himalaya attention has only been paid (e.g. Seeber and Armbruster 1981; Khattri and Tyagi 1983; Baranowski et al 1984; $\mathrm{Ni}$ and Barazangi 1984, 1987) to large and intermediate magnitude earthquakes.

The belt of local earthquakes epicentres investigated by us in the Garhwal Himalaya appears to agree with that deduced from regional and teleseismic data (figure 3). The epicentre of the earthquake of 28 December 1979 was located using local data and by NOAA using regional and teleseismic data. The estimates of the two epicentres differed by $23 \mathrm{~km}$ of map distance. This implies that the epicentral coordinates and focal depths of intermediate magnitude earthquakes are subject to uncertainties of this order. We thus take the view that the agreement between small and intermediate magnitude earthquake epicentre belts may be regarded as tentative and subject to further verification.

Depthwise, the small magnitude earthquakes in the Garhwal Himalaya, according to our estimates, have shallow foci from ground surface down to a depth of about $13 \mathrm{~km}$ in a very large number of cases. On the other hand, the accurate focal depth estimates for intermediate magnitude earthquakes reported by $\mathrm{Ni}$ and Barazangi (1984) and Baranowski et al (1984) are in the range of 12 to $20 \mathrm{~km}$. The possibility of a 
depthwise region of low seismicity in the 12 to $15 \mathrm{~km}$ range has been speculated upon by Chander et al (1985) but bears further investigation. Also, we still hold the view put forward in paper I on the basis of numerical experiments with observed and synthetic data and multilayered wave speed models that the focal depths in the range of 30 to $70 \mathrm{~km}$ reported by ISC and NEIS for Himalayan earthquakes are probably unreliable. This is borne out by the data presented in many figures by $\mathrm{Ni}$ and Barazangi (1984) and Baranowski et al (1984).

The relation of the seismic belt to the MCT is of interest. Seeber and Armbruster (1981) regarded the seismic belt to be down dip of the MCT. Baranowski et al (1984) and Ni and Barazangi (1984) argued that the belt lies between MBT and MCT mostly close to the latter. The same inference was also drawn in paper $I$. However, the surface location of the MCT is a matter of debate among investigators. The trace of the MCT shown in the figures of the present article is taken from the tectonic map of Gansser (1964) because he was one of the propounders of the MCT concept and his map is widely available and frequently referred. The results of seismicity obtained in this article on being combined with those of paper I show that over a distance of about $140 \mathrm{~km}$, the seismic belt follows a straighter course than the surface trace of the MCT. In fact the seismic belt and the MCT criss-cross each other in this part of the Garhwal Himalaya.

The status of the MCT and the MBT in regard to the current seismotectonics of the Himalaya is a matter of debate among the earth scientists. For example, LeFort (1975) considered MCT and MBT as successive tectonic boundary thrusts. MBT is the current boundary of the continental convergence zone while the MCT is a less active or dormant feature. Seeber and Armbruster (1981) argued that MBT and MCT are contemporaneous and that MCT is currently active. Ni and Barazangi (1984) state that it is the MBT and nearby surface and blind thrusts rather than the MCT that are presently the most active structures in the Himalaya. Chander (1987, in press) found that the coseismic ground elevation changes observed during the 1905 Kangra earthquake can be explained only by assuming that slip did not take place on the MBT. Lastly K rishnaswamy et al (1970) observed that coseismic slip did not occur on MBT or any other thrust in the Himalaya. We thus take the view that the current seismotectonics of the Himalaya is associated with buried (or blind) thrust(s) corresponding to the upper surface of the subducting Indian plate.

The main cause of the stresses responsible for the small magnitude earthquakes recorded by us is probably the same as that responsible for relative displacements between the overriding and the subducting plates in the Himalaya. They are likely to be conducive to thrust earthquakes. Locally the elastic (plastic) response of the overriding plate to topographic relief in the underthrusting slab may lead to perturbations of this stress regime. Chandra (1978) put forward the agrument that the normal faulting during the 1975 Kinnaur earthquake, approximately $150 \mathrm{~km}$ north of MCT near $78^{\circ} \mathrm{E}$, was in response to stresses induced by a north-eastward extending salient of the northeast trending Precambrian Aravalli ranges of Rajasthan under the Sindhu-Ganga (Indo-Gangetic) alluvium and the Lesser and High Himalaya. We recapitulate in figure $\mathbf{1 0}$ how the principal stresses for a thrust fault or earthquake can be modified with a superimposed tensile stress to produce principal stresses suitable for strike slip faulting and earthquakes. We thus argue (figure 11) that in the region of GLHSB between the Yamuna and Bhagirathi valleys, the flexing of the overriding rock material in response to the presence of the same Aravalli salient on the under- 


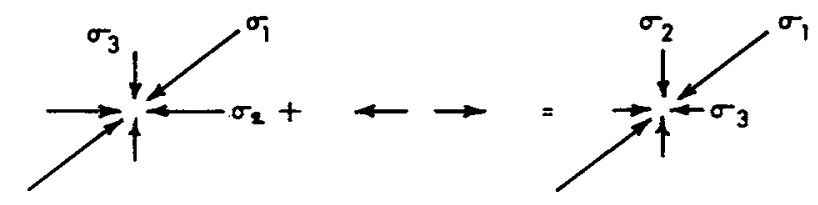
THRUST FAULT STRESS
TENSILE STRESS REGIME DUE TO FLEXURE
STRIKE SLIP FAULT STRESS REGIME

Figure 10. Schematic drawing to show the alteration of a thrust-fault stress regime to a strike-slip fault stress regime due to action of stresses arising from flexure in the lithospheric plate.

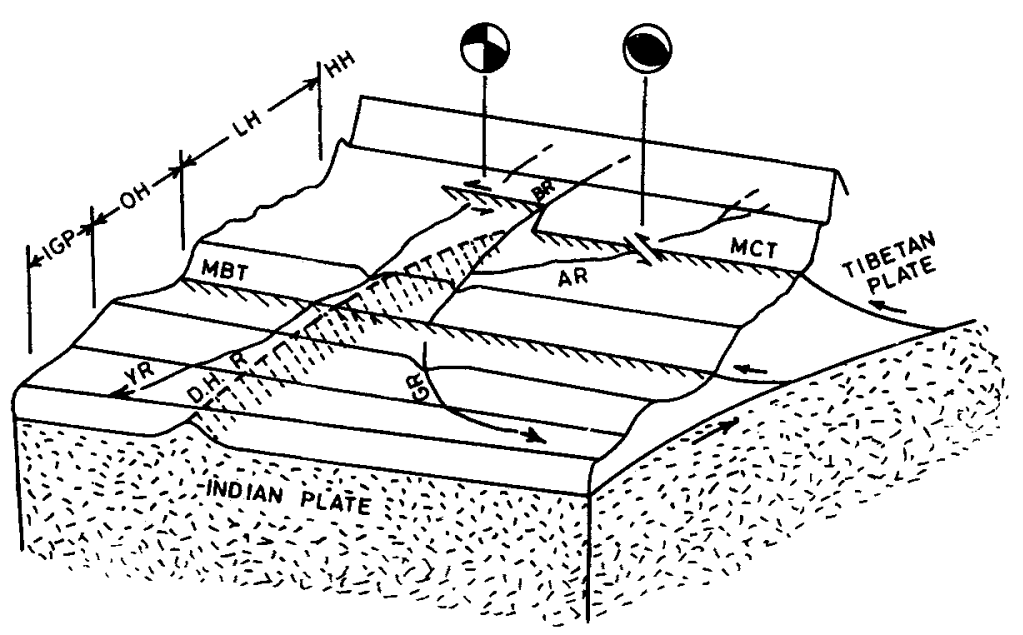

Figure 11. A cartoon to show the origin of flexure in the overriding plate due to topographic relief in the subducting plate. DHR is the Delhi-Hardwar Ridge, a postulated buried northeastward salient of the Pre-Cambrian Aravalli ranges of Rajasthan under the Sindhu Ganga (Indo-Gangetic) Plains (SGP) and Outer (OH), Lesser (LH), Bhagirathi (BR), Ganga (GR) and Yamuna (YR).

thrusting Indian slab gives rise to tensile stresses that modify the configuration of stresses that would have been conducive to thrust earthquakes in the absence of the salient into a stress configuration conducive to strike-slip earthquakes. South east of the Bhagirathi valley, the influence of this superimposed tensile stress regime wanes sufficiently with the result 'thrust' faulting is observed even at shallow levels under the Lesser Himalaya. We however note that in a setting as complex as the Himalaya other processes can give rise to strike-slip faulting.

\section{Conclusions}

(i) Our observations with seismograph arrays of small areal extent in the Garhwal Himalaya have so far shed light only on the small magnitude local earthquakes.

(ii) The belt of local earthquakes has been defined over a distance of $140 \mathrm{~km}$ parallel to the general strike of the mountains in the Garhwal Himalaya. 
(iii) The belt of local earthquakes appears to coincide with the belt of intermediate magnitude earthquakes. However, as uncertainties in the locations of the latter events are greater, this agreement can only be regarded as being tentative.

(iv) The seismic belt follows a straighter course than the outcrop of the MCT in the Garhwal Himalaya and the two criss-cross each other.

(v) The vast majority of earthquakes have focal depths of less than $13 \mathrm{~km}$.

(vi) The first motion data of this paper on being combined with that of paper I indicate strike-slip and thrust mechanisms in operation along the $140 \mathrm{~km}$ length of the GLHSB, investigated. Both solutions indicated a NE-SW oriented compressive maximum principal stress.

(vii) The composite solution indicating thrust-faulting establishes that the overall stress regime in the region is conducive to thrust or reverse fault earthquakes.

(viii) The strike slip earthquakes in the region occupied by the valleys of Yamuna to Bhagirathi, may be the result of an aberration of this stress regime due to tensile stresses induced in the overriding slab, in response to topographic relief on the subducting slab surface.

(ix) The seismic risk in eastern Garhwal Himalaya is high because it lies in the area of a seismic gap along the Himalayan collision zone.

\section{Acknowledgements}

The authors are grateful to the Department of Science and Technology and the Department of Earth Sciences of the University of Roorkee for support of this investigation in all respects.

\section{References}

Agarwal P N and Kumar A 1982 Microearthquake recording for engineering applications. In Engineering geosciences (ed.) B B S Singhal (Meerut: Sarita Prakashan) pp. 181-186

Baranowski J, Armbruster J, Seeber L and Molnar P 1984 Focal depths and fault plane solutions of earthquakes and active tectonics of the Himalaya; J. Geophys. Res. 89 6918-6928

Chandra $U 1978$ Seismicity, earthquakes mechanisms and tectonics along the Himalayan Mountain range and vicinity; Phys. Earth Planet. Inter. 16 109-131

Chander R 1987 On the interpretation of some observations regarding ground level changes during the 1905 Kangra earthquake, NW Himalaya (submitted)

Chander R, Khattri K N, Sangvai P M, Sarkar I and Gaur V K 1985 A strategy for hypocentral parameter estimation for microearthquake surveys at engineering sites; Bull. Indian Soc. Earthquake Tech. 22 1-8

Chander R, Sarkar I, Khattri K N and Gaur V K 1986 Upper crustal compressional wave velocity in the Garhwal Himalaya; Tectonophysics 124 133-140

Dobrin M 1976 Introduction to geophysical prospecting (New York: McGraw Hill Book Co.)

Fitch T J 1970 Earthquake mechanisms and Tectonics in the Himalayan, Burmese and Andaman regions and continental tectonics in central Asia; J. Geophys. Res. 73 777-784

Gansser A 1964 Geology of the Himalayas (New York: Interscience) p. 289

Gaur A 1964 Geology of Himalayas (New York: Interscience) p. 289

Gaur V K, Chander R, Sarkar I, Khattri K N and Sinvhal H 1985 Seismicity and state of stress from investigations of local earthquakes in the Kumaun Himalaya; Tectonophysics 118 243-251

Kaila K L, Reddy R P and Narain H 1968 Crustal structure in the Himalayan foothills area of North India from $P$ wave data of shallow earthquakes; Bull. Seismol. Soc. Am. 58 597-612

Khattri K N 1987 Great earthquakes, seismicity gaps and potential for earthquake disaster along the Himalayan plate boundary; Tectonophysics 38 79-92 
Khattri K N and Tyagi A K 1983 Seismicity patterns in the Himalayan plate boundary and identification of areas of high seismic potential; Tectonophysics 96 281-297

Krishnaswamy V S, Jalote S P and Shome S K 1970 Recent crustal movements in NW Himalaya and gengetic foredeep and related patterns of seismicity; Proc. IV Symp. on Earthquake Engg. Univ. of Roorkee (Meerut: Sarita Prakashan) pp. 419-439

Kumar S, Chander R and Khattri K N 1987 Compressional wave speed in the second crustal layer in Garhwal Himalaya; J. Assoc. Expl. Geophys. 8 219-225

Lyon-Caen H and Molnar P 1983 Constraints on structure of the Himalaya from an analysis of gravity anomalies and a flexural model of the lithosphere; J. Geophys. Res. 88 8171-8191

LeFort P 1975 Himalayas: The collided range. Present knowledge of the collided arc; Am. J. Sci. A275 1-44

Molnar P 1987 The distribution of intensity associated with the 1905 Kangra earthquake and bound on extent of rupture zone; J. Geol. Soc. India $29221-229$

Ni J and Barazangi M 1984 Seismotectonics of the Himalayan collision zone: Geometry of the underthrusting Indian plate beneath the Himalaya; J. Geophys. Res. 89 1147-1163

Richter C F 1956 Elementary seismology (San Francisco: W H Freeman and Co.)

Seeber L and Armbruster J G 1981 Great detachment earthquakes along the Himalayan arc and long term forecasting. In Earthquake prediction. An international review (Washington DC: Am. Geophys. Union)

Seeber L, Armbruster J G and Quittmeyer R C .1981 Seismicity. and continental subduction in the Himalayan arc; Interunion Commission on Geodynamic Working Group 6 Volumes (Washington D.C.: Am. Geophys. Union) pp. 215-242

Srivastava H N 1986 Status of seismicity and observational networks. In Proceedings of the National Meet of Earthquake Mechanism and Mitigation, Department of Science and Technology, Government of India, New Delhi, pp. 51-58

Tandon A N and Dubey R K 1973 A study of crustal structure beneath the Himalaya from body waves; Pure Appl. Geophys. 3 2207-2216

Valdiya K S 1980 Geology of the Kumaun Himalaya (Dehradun: Wadia Institute of Himalayan Geology) p. 289

Valdiya K S 1986 Neotectonies activities in the Himalayan belt; Proceedings of International Symposium on Neotectonics in South Asia (Dehradun Survey of India) p. 434

Verma G S 1974 Structure of the foothills of the Himalaya; Pure Appl. Geophys. 112 18-76

Wadia D N 1953 Geology of India (London: Macmillan and Co.) p. 531 